\title{
Airborne Lidar Observations of Water Vapor Variability in Tropical Shallow Convective Environment
}

\author{
Christoph Kiemle, Silke Groß, Martin Wirth, and Luca Bugliaro \\ DLR, Deutsches Zentrum für Luft- und Raumfahrt, Institut für Physik der Atmosphäre \\ D-82234 Oberpfaffenhofen, Germany
}

Received: 7 October 2016 / Accepted: 21 September 2017 / Published online: 4 October 2017

The final publication is available at link.springer.com

\begin{abstract}
An airborne downward-pointing water vapor lidar provides two-dimensional, simultaneous curtains of atmospheric backscatter and humidity along the flight track with high accuracy and spatial resolution. In order to improve the knowledge on the coupling between clouds, circulation and climate in the trade wind region, the DLR (Deutsches Zentrum für Luft- und Raumfahrt) water vapor lidar was operated on board the German research aircraft HALO during the NARVAL (Next Generation Aircraft Remote Sensing for Validation Studies) field experiment in December 2013. Out of the wealth of about 30 flight hours or $25000 \mathrm{~km}$ of data over the Tropical Atlantic Ocean east of Barbados, three $\sim 2 \mathrm{~h}$ long, representative segments from different flights were selected. Analyses of Meteosat Second Generation (MSG) images and dropsondes complement this case study. All observations indicate a high heterogeneity of the humidity in the lowest $4 \mathrm{~km}$ of the tropical troposphere, as well as of the depth of the cloud (1-2 km thick) and sub-cloud layer ( $1 \mathrm{~km}$ thick). At the trade inversion with its strong humidity jump of up to $9 \mathrm{~g} / \mathrm{kg}$ in water vapor mixing ratio, the mixing ratio variance can attain $9(\mathrm{~g} / \mathrm{kg})^{2}$ while below it typically ranges between 1 and $3(\mathrm{~g} / \mathrm{kg})^{2}$. Layer depths and partial water vapor columns within the layers vary by up to a factor of 2 . This affects the total tropospheric water vapor column, amounting on average to $28 \mathrm{~kg} / \mathrm{m}^{2}$, by up to 10 $\mathrm{kg} / \mathrm{m}^{2}$ or $36 \%$. The dominant scale of the variability is given by the extent of regions with higherthan-average humidity and lies between $300-600 \mathrm{~km}$. The variability mainly stems from the alternation between dry regions and moisture lifted by convection. Occasionally, up to $100 \mathrm{~km}$ large dry regions are observed. In between, convection pushes the trade inversion upward, sharpening the vertical moisture gradient that is co-located with the trade inversion. In most of the water vapor profiles this gradient is stronger than the one located at the top of the sub-cloud layer. Lidar observations, in concert with models accurately reproducing the observed variability are expected to help evaluate the role these details play for climate.
\end{abstract}

Keywords: Airborne lidar, water vapor lidar, shallow convection, trade wind region, cloud layer 


\section{Introduction}

The WCRP (World Climate Research Programme) "Grand Challenge on Clouds, Circulation and Climate Sensitivity" endorses scientific progress in our understanding of the coupling between clouds, circulation and climate. In this context, the variability of water vapor in the trades, ubiquitous in our measurements, poses challenges to climate modeling because it modulates the low-cloud cover and eventually Earth's albedo (Bony et al., 2017). Besides being the precondition for cloud formation, the importance of water vapor in the trades is twofold. It lifts latent heat from the ocean surface via convection, and it is a key player in the radiation budget. Above the trade inversion, the almost absence of water vapor in the subsiding branch of the Hadley cell has the effect of an open window in a greenhouse, efficiently cooling the lower troposphere in the trades. Generally, the influence of water vapor on tropospheric heating rates depends on the vertical distribution of water vapor and on the strengths of its vertical gradients, both of which current water vapor observations, particularly from space, have difficulties in reproducing (Stevens et al., 2017). Secondary circulations between radiatively heated and cooled regions are supposed to occur (Zuidema et al., 2017) which adds complexity to the situation. The interactions between shallow convection, circulation and radiation are at the heart of present scientific debate. They are held mainly responsible for the uncertainty in global climate sensitivity (see, e.g., Sherwood et al., 2014; Bony et al., 2015; WCRP, 2016).

This case study focuses on water vapor lidar measurements obtained during the NARVAL (Next Generation Aircraft Remote Sensing for Validation Studies) field experiment around Barbados. From 10 to 20 December 2013 the DLR airborne demonstrator WALES (Water vapor Lidar Experiment in Space; Wirth et al., 2009) was operated on board the German research aircraft HALO. A total of eight research flights were performed: four long-range transfer flights crossing the subtropical North Atlantic between Oberpfaffenhofen, HALO's home base in Southern Germany, and Barbados, and four regional flights out of Barbados between $10-19^{\circ} \mathrm{N}$ and $39-59^{\circ} \mathrm{W}$ within the winter trades over the Tropical Atlantic Ocean. Dropsondes and a set of additional remote sensors were on board, including radar and microwave radiometers (Mech et al., 2014), as well as spectrometers measuring the up- and downwelling radiances. The ample and unique instrumentation evidently calls for a synergistic retrieval of the full suite of remote sensors that is pending. Meteosat Second Generation (MSG) satellite imagery and dropsonde profiles complement the lidar observations here. In August 2016 NARVAL was repeated with the same payload yet modified objectives and flight patterns (Stevens et al., 2017), generally located closer to the ITCZ than the measurements described here.

NARVAL lines up in a long list of scientific experiments in the trades. For example, water vapor and its variability were measured in-situ on board aircraft, e.g. LeMone and Pennell (1976), or ships, e.g. Zuidema et al. (2012). Nuijens et al. (2015) use ground-based lidar measurements of trade-wind clouds and find that climate models have difficulties in reproducing the observed variability. To our knowledge, airborne water vapor lidar observations in tropical shallow convective environment have not been reported yet, despite the well-documented need for water vapor profiling with higher accuracy and higher vertical resolution than the current observations provide (Wulfmeyer et al., 2015; Pincus et al., 2017; Stevens et al., 2017). Earlier own work has demonstrated the value of airborne lidar observations to characterize the variability of humidity within the convective boundary layer over flat and mountainous terrain (Behrendt et al., 2007; Kiemle et al., 2011), as well as in the free troposphere (Flentje et al., 2005; Fischer et al., 2013), the tropical upper troposphere (Kiemle et al., 2008) and in cirrus clouds (Groß et al., 2014). In combination with a scanning Doppler wind lidar 
measuring horizontal winds, the advective tropospheric moisture transport along a curtain below the aircraft can be quantified (Schäfler et al., 2010). Eddy correlation of the Doppler lidar vertical velocity and of the water vapor lidar data curtains delivers profiles of the latent heat flux in a convective boundary layer (Kiemle et al., 2007 and 2011). This dual-lidar combination did not exist for NARVAL because the mission goals focused on radar-lidar comparisons, unfortunately not leaving enough space for a wind lidar on board HALO. The cross-Atlantic NARVAL transfer flights show dry layers and related synoptic-scale humidity variability in the mid- to upper-troposphere, connected to tropopause folds that are dynamically linked to the subtropical jet, as has been observed, e.g., by Flentje et al. (2005) or Randel et al. (2016). This upper-level variability observed above the trade inversion extends equatorward yet is not topic of the paper. Cloud statistics as in Nuijens et al. (2015) and comparisons with satellite observations of clouds are addressed in a parallel study by Gutleben et al. (2017). This paper provides support to the preparation of future planned airborne (Bony et al., 2017) and spaceborne (Di Girolamo et al., 2008) water vapor lidar deployments. By showcasing selected measurement examples it complements the more general overview on emerging technologies for measuring water vapor in the lower troposphere by Nehrir et al. (2017).

\section{The DLR Airborne Water Vapor Lidar}

A differential absorption lidar (DIAL) emits short and spectrally narrow laser pulses at a wavelength tuned to the center (in the case of WALES) or to a wing position of a molecular water vapor absorption line. The water vapor density can be derived from the difference in absorption between one or more "on-line" and a reference "off-line" pulses as function of distance from the lidar. DLR's airborne water vapor lidar WALES (Wirth et al., 2009) consists of two identical diode-pumped $\mathrm{Nd}$ :YAG lasers in a master-oscillator power-amplifier configuration with a pulse repetition rate of 100 $\mathrm{Hz}$. Their frequency-converted 532-nm radiation pumps two optical parametric oscillators (OPO). Each OPO generates two wavelengths in the $935 \mathrm{~nm}$ absorption band of water vapor. A water vapor absorption cell and a wave-meter control and stabilize all four wavelengths, three on-line and one off-line. The pump light not converted to $935 \mathrm{~nm}$ is transmitted into the atmosphere for aerosol and cloud measurements, and is received with a high-spectral-resolution detector. Due to its capabilities the WALES airborne demonstrator has become a state-of-the-art instrument for climate and meteorological research. Over the past decade it successfully completed several hundreds of flight hours in national and international field campaigns (Schäfler et al., 2010; Bhawar et al., 2011; Kiemle et al., 2011; Bielli et al., 2012; Fischer et al., 2013; Groß et al., 2014; Trickl et al., 2016).

During NARVAL a typical HALO flight altitude of $13 \mathrm{~km}$ was selected, being the result of a compromise between radar operation constraints and maximum vertical coverage for lidar and dropsondes. The altitude is higher than during former experiments targeting lower-tropospheric moisture which has implications for the lidar signal-to-noise ratio. In order to reduce instrument noise to acceptable levels the individual on- and off-line DIAL profiles are accumulated to 12-s averages, which results in a horizontal resolution of $2.8 \mathrm{~km}$ at a typical aircraft speed of $230 \mathrm{~m} / \mathrm{s}$. The vertical resolution is 290 $\mathrm{m}$. The lidar backscatter signal is less affected by noise. Here the horizontal (vertical) resolution is 230 (15) $\mathrm{m}$. Consequently, small clouds are detected only in the lidar backscatter, and gaps $<\sim 3 \mathrm{~km}$ between clouds are too small to obtain water vapor lidar profiles down to the surface. Nevertheless the mesoscale water vapor variability is sufficiently well resolved for the goals of this study. 
Differential absorption lidar measures molecule number density. Conversion into the mass mixing ratio, useful for thermodynamic relations, requires knowledge of dry air density, usually obtained by ECMWF analysis fields of atmospheric pressure and temperature that are interpolated in space and time to the lidar measurement positions. When available, a profile of air density is provided by the closest dropsonde.

On average over all available inter-comparisons, the typical deviations between lidar and dropsonde mixing ratio profiles amount to a few percent, which corroborates the results of lidar intercomparisons by Bhawar et al. (2011) and Trickl et al. (2016). Total or partial columns of water vapor are obtained by vertical integration of absolute humidity, the product of mass mixing ratio and dry air density. Due to methodical constraints, water vapor lidar data below $250 \mathrm{~m}$ above sea level (asl) are not available. Given typical surface mass mixing ratios of around $13 \mathrm{~g} / \mathrm{kg}$ (see Table 1 ) this amounts to about $4 \mathrm{~kg} / \mathrm{m}^{2}$ that are missing in the lidar-derived columns, which represents $14 \%$ of a typical total column of $28 \mathrm{~kg} / \mathrm{m}^{2}$. To solve this issue we assume the unknown mixing ratios below 250 $\mathrm{m}$ to be identical to those measured at $250 \mathrm{~m}$. We find agreement within a few percent between the resulting lidar-derived columns and the dropsonde results of Table 1, which is consistent with the abovementioned lidar accuracy and consequently validates our approach.

\section{The Meteosat Images}

To obtain an overview of the general cloud situation at the time of the flight, false color composites have been produced using data from the imaging radiometer SEVIRI (Spinning Enhanced Visible and Infrared Imager; Schmetz et al., 2002) aboard the geostationary satellite Meteosat Second Generation (MSG) located at the equator above $0^{\circ} \mathrm{E}$. SEVIRI combines a temporal resolution of 15 minutes with 12 channels in the solar and thermal spectral range. Its sampling distance amounts to 3 $\mathrm{km}$ in 11 channels at the sub-satellite point while the broadband High Resolution Visible (HRV) channel has a sampling distance of $1 \mathrm{~km}$. The colors red and green are produced by the superimposition of the low resolution solar channels centered at 0.6 and $0.8 \mu \mathrm{m}$ with the HRV channel to produce a high resolution picture. The blue color stems from the low resolution thermal channel centered at $10.8 \mu \mathrm{m}$ such that the blue component is high for cold objects (like ice clouds) and low for warm objects (like low clouds). In more detail, the blue color ranges from 263 (maximum blue saturation) to $323 \mathrm{~K}$ (no blue component). In this color scheme, the sea surface appears deep blue/black since it shows very low solar reflection (apart from sun glint regions) and is warm. Very low clouds appear yellow because of their relatively high reflection (high $\mathrm{R}$ and $\mathrm{G}$ components) and comparatively high temperature (low B component). Thicker clouds appear white since they are both highly reflective and cold. Thin cirrus appears bluish / violet because it reflects little solar radiation and is very cold. The different height of thick mid-level white clouds and high thin blueish cirrus clouds (sporadically present in the images presented in the following) can also be inferred from the distance between the clouds themselves and the shadow they cast onto the lower lying objects (sea surface, lower clouds, aerosol layer) due to the low lying sun: this exercise confirms that blueish objects are higher in the atmosphere than white objects. The clouds sensed by the airborne lidar are marked on these false color composites. A parallax correction has been applied under the assumption that the cloud top is at around $2 \mathrm{~km}$ height above the sea surface. The part of the flight path closest in time to the given SEVIRI slot, indicated by the start time of the scan in the top left corner of the figures, is plotted in cyan, while the flight route is red otherwise. The cyan cross 
denotes the point where the aircraft and SEVIRI are observing almost simultaneously. The corresponding UTC time is written in cyan next to it. All SEVIRI figures are in satellite projection.

\section{Results}

\subsection{Overview}

Out of the wealth of lidar data in the tropics, about 30 flight hours or $25000 \mathrm{~km}$, we select three 2.0 to $2.5 \mathrm{~h}$ long, representative segments from different flights in the Western Atlantic Ocean, to the east of Barbados, between 21 and $14^{\circ} \mathrm{N}$, north of the ITCZ. Our selection avoids aircraft turns, measurement interruptions, unavailability of dropsondes and fully overcast areas. Each segment showcases a topic of particular scientific interest. Table 1 gives an overview of the main characteristics of all segments, as well as of basic meteorological parameters obtained by the sondes dropped within the segments. We used the Vaisala RD94 GPS dropsondes that measure relative humidity with two independent sensors. After conversion into mass mixing ratio we find deviations between both sensors of $<0.5 \mathrm{~g} / \mathrm{kg}$, which roughly corresponds to the lidar accuracy. All sondes were processed using the ASPEN V3.3-270 software and the data was further visually inspected for possible biases or malfunction before being incorporated into the analysis. All sondes probed similar meteorological and thermodynamic conditions, owing to the trade wind regime and the ocean surface. Their lowest measurements in the atmosphere just above the ocean surface provide a good proxy of surface temperature and surface humidity. Both increase equatorward as expected, while surface pressure decreases. Total column water vapor however, the vertically-integrated absolute humidity, does not show a clear latitudinal dependency within our study area. It depends rather on the depth and humidity of an elevated moist layer with embedded clouds, termed cloud layer (Stevens, 2005), which typically extends up to between 2 and $3 \mathrm{~km}$ asl in Figure 1 and the lidar observations below. 


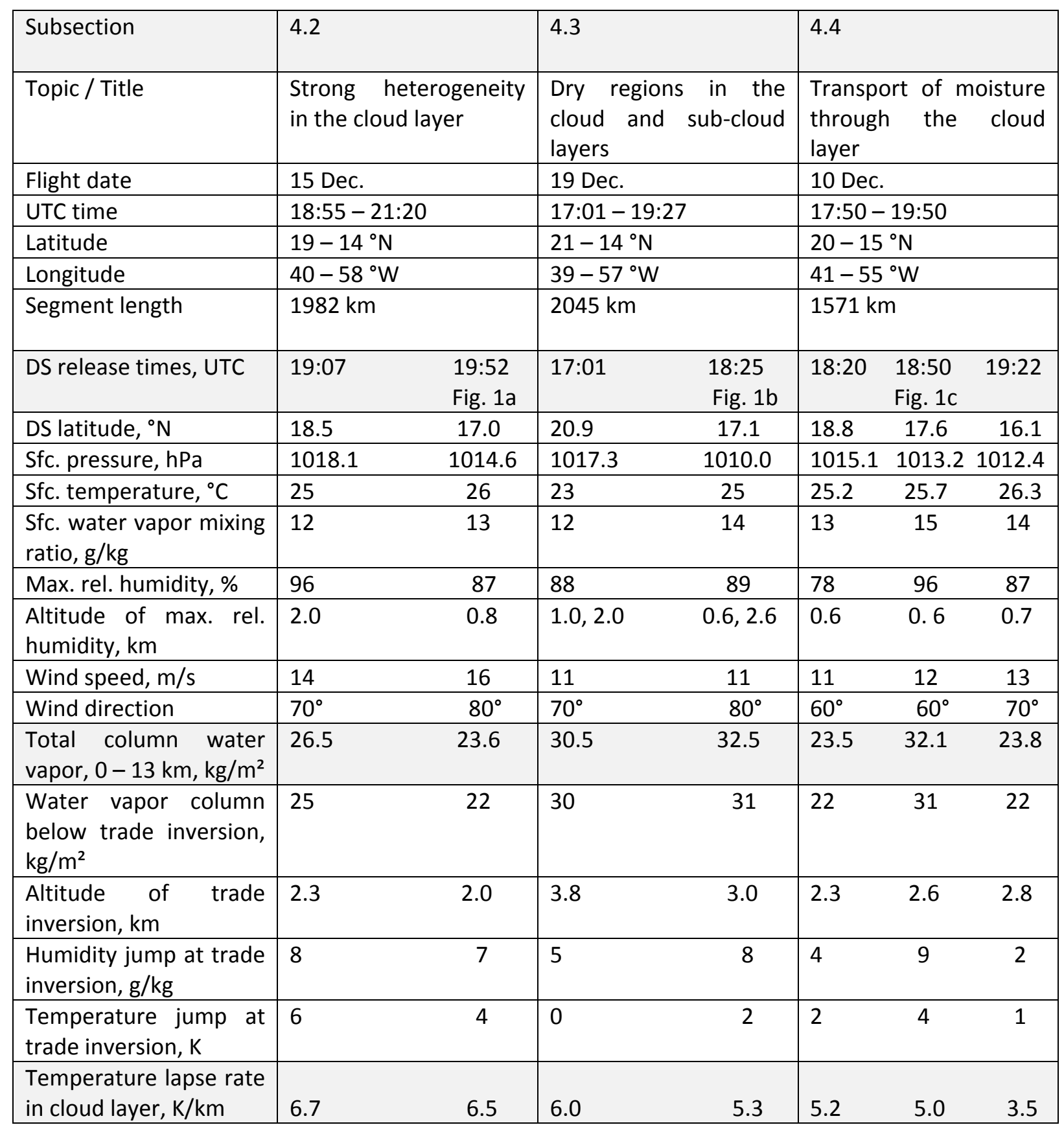

Table 1: Main characteristics of the 3 selected lidar segments and of 7 related dropsondes (DS). Wind speed and direction ( $0^{\circ}$ is wind from north) are averaged over the dropsondes' lowest $3 \mathrm{~km}$. All flights went from northeast to southwest in a straight line without turn, at $\sim 13 \mathrm{~km}$ flight altitude. Local time is UTC $-4 \mathrm{~h}$. When the relative humidity exceeds $95 \%$ the dropsonde likely passed through a cloud.

Figure 1, a sample of 3 sondes related to the lidar results, gives an overview of the thermodynamic situation in the lowest $4 \mathrm{~km}$, mainly the trade wind layer. Since all segments lie within the downward subsiding branch of the tropical Hadley cell, we see a strong capping inversion at the cloud layer top, termed trade inversion (Stull, 2015) accompanied by a strong gradient in water vapor mixing ratio. Below, the cloud layer extends down to about $0.8 \mathrm{~km}$ asl with conditionally unstable temperature 
lapse rates varying between 3.5 and $6.7 \mathrm{~K} / \mathrm{km}$ in Table 1 . Under such conditions a saturated parcel of air is unstable to upward vertical displacements, and an unsaturated parcel is stable to small displacements. Slight variations in temperature and mixing ratio, as visible in Figure 1, can suffice for saturation, or under-saturation, to occur. In the lowest level, the cloud-free, convective marine boundary layer is characterized by fairly zero vertical gradients in water vapor mixing ratio and potential temperature, indicating well-mixed conditions. Its temperature lapse rate in these 3 exemplary cases varies between 10.0 and $10.5 \mathrm{~K} / \mathrm{km}$, very close to dry adiabatic conditions. This subcloud layer is capped by a weaker inversion, accompanied by a smaller mixing ratio jump of roughly 4 $\mathrm{g} / \mathrm{kg}$. Table 1 shows that the relative humidity mostly peaks at the top of this sub-cloud layer. The average total column water vapor in Table 1 amounts to $28 \mathrm{~kg} / \mathrm{m}^{2}$. As typical for the winter trades, the humidity below the trade inversion accounts for $\sim 95 \%$ of that column, the partial column above totals $\sim 1.4 \mathrm{~kg} / \mathrm{m}^{2}$. These dropsonde observations agree with the lidar results hereafter.
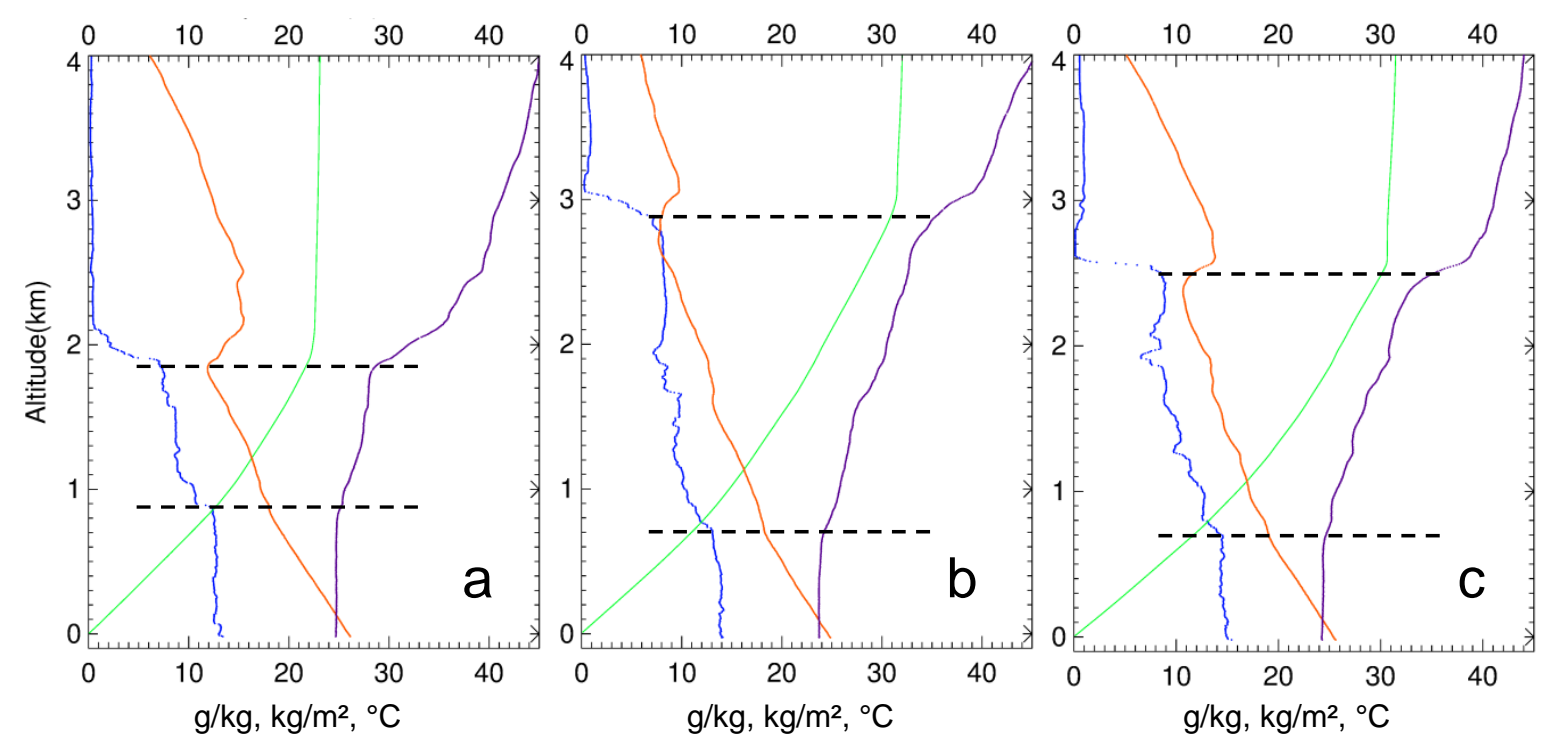

Figure 1: lower-tropospheric profiles of 3 selected radiosondes dropped from the aircraft; a) 15 Dec. 2013 19:52 UTC,b) 19 Dec. 2013 18:25 UTC, c) 10 Dec. 2013 18:50 UTC. Water vapor mixing ratio (blue), bottom-integrated water vapor column (green), temperature (orange) and potential temperature (violet). Dashed lines: heights of cloud layers from lidar observations. Table 1 lists additional data from these sondes.

We dedicate each of the three following subsections to a different physical phenomenon or process, even if it is evident that the presented lidar examples show similarities, owing to the overall comparable meteorological conditions. Common features of the lidar observations include (a) the horizontal and vertical variability of humidity in the lowest $4 \mathrm{~km}$, our key topic, (b) the omnipresence of an elevated moist layer with embedded clouds, the cloud layer, (c) the predominance of two altitudes for shallow clouds, namely the bottom and the top of the cloud layer, and (d) the absence of moist and aerosol layers in the free troposphere above the cloud layer. The latter is related to the winter trades with the lowest likelihood of cross-Atlantic Sahara dust transport (Prospero et al., 2014). The absence of aerosol from remote, continental origin eases the interpretation and the 
comparison between the lidar backscatter and water vapor measurements, as sea salt aerosol and evaporation, both originating at the sea surface, can be considered here the main sources for the observed backscatter and moisture, respectively.

\subsection{Strong heterogeneity in the cloud layer}

On 15 Dec. 2013 a local flight with start and landing in Barbados was performed in southwestnortheast-southwest sequence, interrupted by a north-south under-flight of the NASA A-Train satellites during the outbound flight leg, as displayed in Figure 2. While the southwest part of the flight has few clouds, the northeast part shows large cloud clusters with smaller cloud-free zones in between. The overflown clouds can well be compared with the lidar backscatter in Figure 3 which shows the way back to Barbados where the aircraft was heading straight southwest, without another A-Train underflight, and nearly parallel with the trade wind blowing at $\sim 15 \mathrm{~m} / \mathrm{s}$ (Table 1 ) yet 15 times faster. The resulting maximum deviations of the lidar measurements at 40 and $54^{\circ} \mathrm{W}$, separated in time by $\sim 1 \mathrm{~h}$ from Figure 2, are $\sim 54 \mathrm{~km}$ or $\sim 0.5$ degrees longitude. Not only do the large scale patterns coincide, but also small clouds around 19:53 are visible in both satellite and lidar images at about $1 \mathrm{~km}$ asl. The smallest clouds though are difficult to distinguish in both figures. They appear as black dots in the lidar image and as an unresolved yellow-brown background in the satellite image, where very low faint clouds in between the many little white (i.e. higher and thicker) cloud tops with horizontal extensions well below the satellite spatial resolution altogether result in a fairly uniform yellow-brown color. At 19:30, in between two large cloud clusters, the top panel of Figure 3 shows a cloud-free region $\sim 70 \mathrm{~km}$ in width with maritime aerosol in the sub-cloud layer and less backscatter in the cloud layer. This corresponds in Figure 2 to a uniform yellow-brown area at the intersection of the red flight path and $44.3^{\circ} \mathrm{W}$. Comparing our two examples around 19:30 and 19:53, we conclude that it is nearly impossible to distinguish small, scattered low clouds from fully cloud-free regions in the MSG imagery because of the omnipresence of sea salt aerosol in the lowest layer which hides the expected darker ocean surface, and because of the MSG/SEVIRI pixel size (large with respect to the lidar) that reduces the probability of observing a fully cloud-free area. An exceptionally dark area is found in Figure 2 at $54.2 \mathrm{~W}$ corresponding to Figure 3 at 21:12. A region about $40 \mathrm{~km}$ wide, with backscatter coefficients two times lower than in the previous example in both the sub-cloud and the cloud layer, is observed by the lidar. Another dark region is seen in the next sub-section, in Figure 4 at $56.2 \mathrm{~W}$ and in Figure 5 at 19:18 with additionally both layers thinner. These dark regions represent spots in the MSG images where reflectivity at $0.6 \mu \mathrm{m}$ is as low as $\sim 0.13$ and reflectivity at $0.8 \mu \mathrm{m}$ is below 0.08 , indicating a cloud-free environment with low aerosol content. Aerosol variability is present and visible in detail in the lidar backscatter, yet difficult to quantify. Larger lidar backscatter can be due to larger aerosol sizes and concentrations. Hydrophilic sea salt particles swell with increasing relative humidity, observed at the top of the sub-cloud layer, while their concentrations increase with increasing surface winds, ocean roughness and intensity of turbulent mixing. 


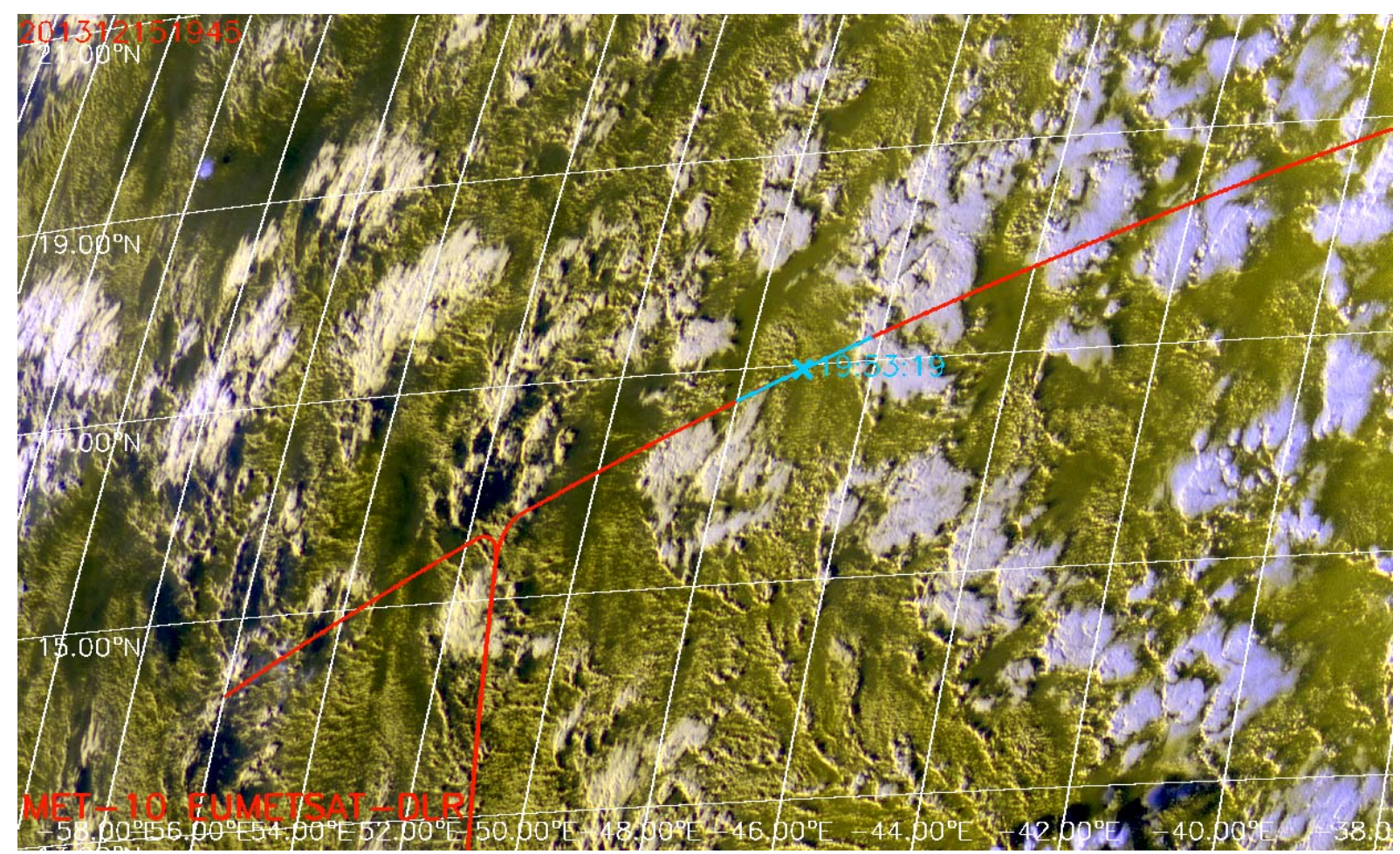

Figure 2: MSG/SEVIRI false color composite for 15 Dec. 2013 at 19:45 UTC using the 0.6, 0.8 and 10.8 $\mu \mathrm{m}$ channels together with the high resolution visible channel. The sea surface appears dark, low clouds yellow, thick clouds white. See section 3 for details. Aircraft flight track superposed (red), between 18:55 (northeast) and 21:05 (southwest end of red line), with 15-min segment around 19:53 highlighted in blue, corresponding to the part of the flight path closest in time to this image. The north-south excursion at $\sim 51 \mathrm{~W}$ was an underflight of the NASA A-Train, yet during the earlier outbound flight part around 17:00 UTC. The distance between 2 degrees in longitude is $\sim 213 \mathrm{~km}$, between 2 degrees in latitude $\sim 223 \mathrm{~km}$. Barbados is situated approximately in the lower left corner, at $13^{\circ} \mathrm{N}, 59^{\circ} \mathrm{W}$. 

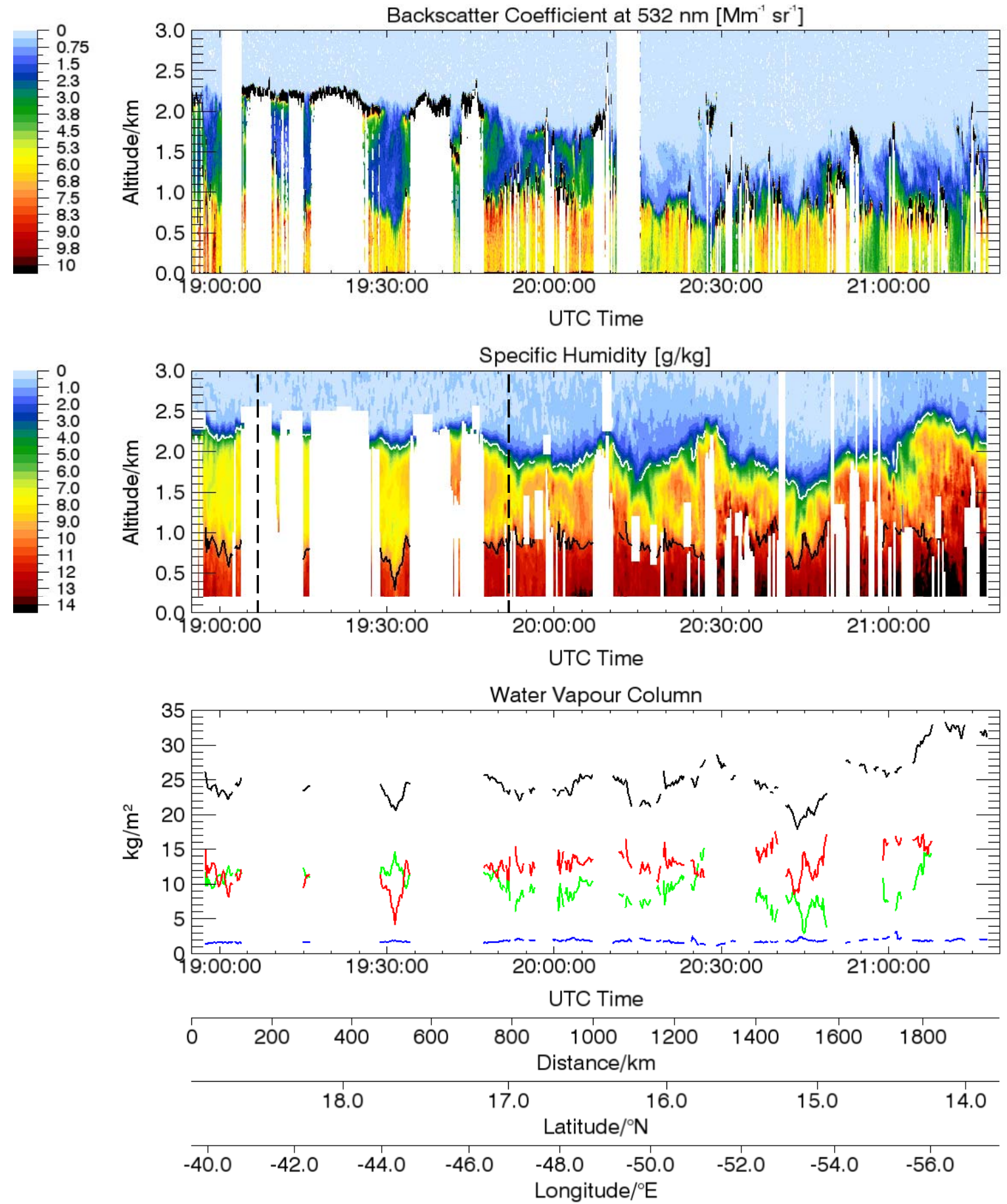

Figure 3, top: High spectral resolution lidar (HSRL) backscatter of the lower tropical troposphere on 15 Dec. 2013; clouds black. Middle: Water vapor lidar cross section with dropsondes from Table 1 as dashed lines. The top of the cloud layer (white line) is defined by a threshold in mixing ratio of $4 \mathrm{~g} / \mathrm{kg}$, the top of the sub-cloud layer by one of $10 \mathrm{~g} / \mathrm{kg}$ (black line; $11 \mathrm{~g} / \mathrm{kg}$ after 19:45 UTC). Missing or too noisy data, mainly below clouds, are whitened. The lidar images are squeezed in the horizontal by a factor of $\sim 200$ with respect to the vertical. Bottom: Total water vapor column between $0-13 \mathrm{~km}$ (black) and partial columns of the sub-cloud layer (red), the cloud layer (green) and the column aloft (blue). The columns are undefined when data are missing. 
Figures 2 and 3 reveal a structural difference between the large upper-level cloud cover in the northeast and the more scattered, small and multi-level cloud occurrences in the southwest. The dropsonde of Figure $1 \mathrm{a}$ is located at the transition between both cloud regimes. Moist convection is obviously responsible for lifting the cloud layer, e.g., at around 20:08, 20:28 and 20:54 UTC, and also the sub-cloud layer, e.g., at 20:00 and 20:32 UTC. The absence of high-resolution observations of vertical motion however hinders a more consolidated statement to this respect. Thresholds in the mixing ratio reveal more robust than maxima in vertical mixing ratio gradients to separate the layers. We tested both gradient and threshold methods. The gradient method works well for determining the upper layer limit, where it coincides within $\sim 100 \mathrm{~m}$ with a threshold of $4 \mathrm{~g} / \mathrm{kg}$ (the white line). The top of the sub-cloud layer however has a gradient so much weaker that the threshold gives more robust results, albeit not always satisfying. The black line in the middle panel of Figure 3, outlining the top of the sub-cloud layer, mostly coincides well with the strong vertical aerosol backscatter gradients in the top panel, except after 20:50 UTC, where the lower part of the cloud layer is more humid. Here the threshold method fails, and data where the sub-cloud layer height would have exceeded $1.2 \mathrm{~km}$ have been removed. This is the maximum thickness of the sub-cloud layer in the lidar backscatter. The alternative to use the backscatter gradients fails due disparities between the distributions of aerosol and humidity, and due to the frequent absence of aerosol at the cloud layer top.

Overall, the strong heterogeneity of layer depth, humidity, cloud, and aerosol distribution of the cloud and sub-cloud layers marks the scenery. For example, at an altitude of $1.5 \mathrm{~km}$, in the middle of the cloud layer, the lidar-observed mixing ratio varies by a factor of 3 , between about 3 to $10 \mathrm{~g} / \mathrm{kg}$, which influences a lot the water vapor columns. The partial columns in both layers (red and green lines for the sub-cloud and cloud layers, respectively) vary by up to a factor of 2 , and the total column (black) by up to $10 \mathrm{~kg} / \mathrm{m}^{2}$ or $30 \%$. The wavy variations in the total column have a size of about 300 $\mathrm{km}$, corresponding roughly to the extent of regions with higher-than-average humidity, interrupted by smaller dry regions.

\subsection{Dry regions in both cloud and sub-cloud layers}

This case has been observed 4 days later on 19 Dec. 2013 along nearly the same flight track, with little more extent towards the northeast. In comparison with Figure 2, Figure 4 shows large cloud clusters aligned northeast-southwestward in the west and less cloudiness in the northeast. Indeed, in Table 1, the 17:01 UTC dropsonde has slightly lower relative humidity, compared to the 19:07 UTC dropsonde of the previous case. Again, in Figure 5, we see humidity heterogeneity and the presence of two dominant cloud levels. However, the total water vapor is $20 \%$ higher, because the cloud layer is on average $1 \mathrm{~km}$ thicker, while the sub-cloud layer is very similar, as also seen in Figures $1 \mathrm{a}$ and $1 b$. The partial columns of water vapor of both layers show less variability in this case. Due to the thickness of the cloud layer, its column content now mostly equals that of the sub-cloud layer. Still, variations of the partial columns of both layers occasionally exceed a factor of 2 . Conditional instability in the cloud layer, documented in Figure 1 and Table 1, leads to the observed patchiness of convection. Uplifted by local convergence due to, e.g., shallow secondary circulations, a parcel of air may saturate at any height within the cloud layer, as observed in the lidar backscatter. On the other hand the growth of clouds may be stopped by weak temperature inversions within the cloud layer, as seen for example in Figure $1 \mathrm{~b}$ at $1.7 \mathrm{~km}$ asl, corroborated by the presence of cloud tops in Figure 5 at 
this height. Besides the particularly high reaching humidity, a dry region at 18:40 UTC is eye-catching in Figure 5. Dry regions were also observed in the previous case, but this event is nearly as dry as the free troposphere in the middle of the cloud layer in $2 \mathrm{~km}$ asl. The total water vapor column decreases by $10 \mathrm{~kg} / \mathrm{m}^{2}$ or $\sim 30 \%$ across a width of $\sim 100 \mathrm{~km}$, and the near-surface humidity still by about $2 \mathrm{~g} / \mathrm{kg}$ (15\%). Because the water column aloft is dry, and because upper-tropospheric clouds are absent, such regions significantly cool the lower troposphere (Stevens et al., 2017). It is this variability of water vapor and of the trade inversion height that modulates the amount of outgoing longwave radiation and the related cooling rates. The amount of cooling and the occurrence of possibly induced secondary circulations are a focus of current research (Zuidema et al., 2012 and 2017). In addition, radiative cooling may promote convection and clouds, and may be at the origin of convective aggregation, another focus of current research (Stevens et al., 2017).

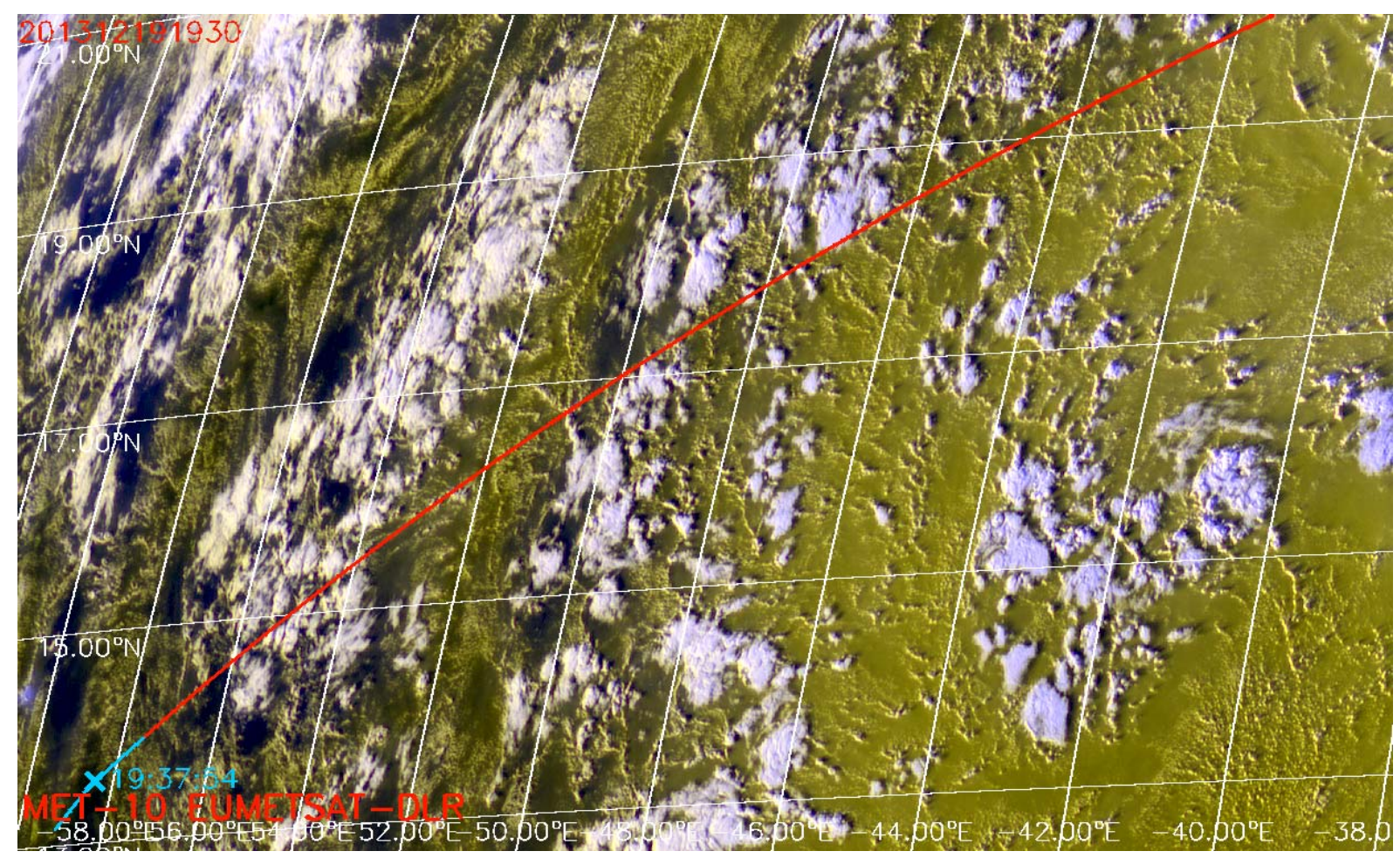

Figure 4: as Figure 2 but for the 19 Dec. 2013, 19:30 UTC. Aircraft flight track starting 17:20 (northeast end of red line), with 15-min segment around 19:38 UTC highlighted in blue, corresponding to the part of the flight path closest in time to this image.

The high-humidity regions in the cloud layer in Figure 5 span across $~ 500 \mathrm{~km}$, which is larger than in the previous case. This scale is again best deduced from the variations of the total column water vapor (black line), where we find higher levels between 18:00 - 18:40, and 18:40 - 19:20. The cloud layer extends nearly up to $4 \mathrm{~km}$ height in the northeast. Less subsidence in this northernmost part is a likely reason, since the 17:01 dropsonde profile (not shown here) has a much weaker inversion and moisture gradient than the 18:25 dropsonde of Figure $1 \mathrm{~b}$. We also find dry regions in the sub-cloud layer, also $\sim 100 \mathrm{~km}$ in size. At 17:10, for example, the sub-cloud water column decreases by nearly $10 \mathrm{~kg} / \mathrm{m}^{2}$. Unlike their counterparts in the cloud layer these dry regions probably do not affect radiation as much since they lie underneath the moist, insulating cloud layer. The 17:01 dropsonde, 
although not quite hitting the driest part of the sub-cloud layer, measured a 2 degrees lower surface temperature than the 18:25 dropsonde (see Table 1). These dry regions obviously occur where the sub-cloud layer is thinner, as Figure 5 shows. Overall, we find high variability in the depth of the subcloud layer. In this segment for example, it varies between $\sim 700 \mathrm{~m}$ (at 17:37 or 19:18) and $\sim 1300 \mathrm{~m}$, which is nearly a factor of 2 .
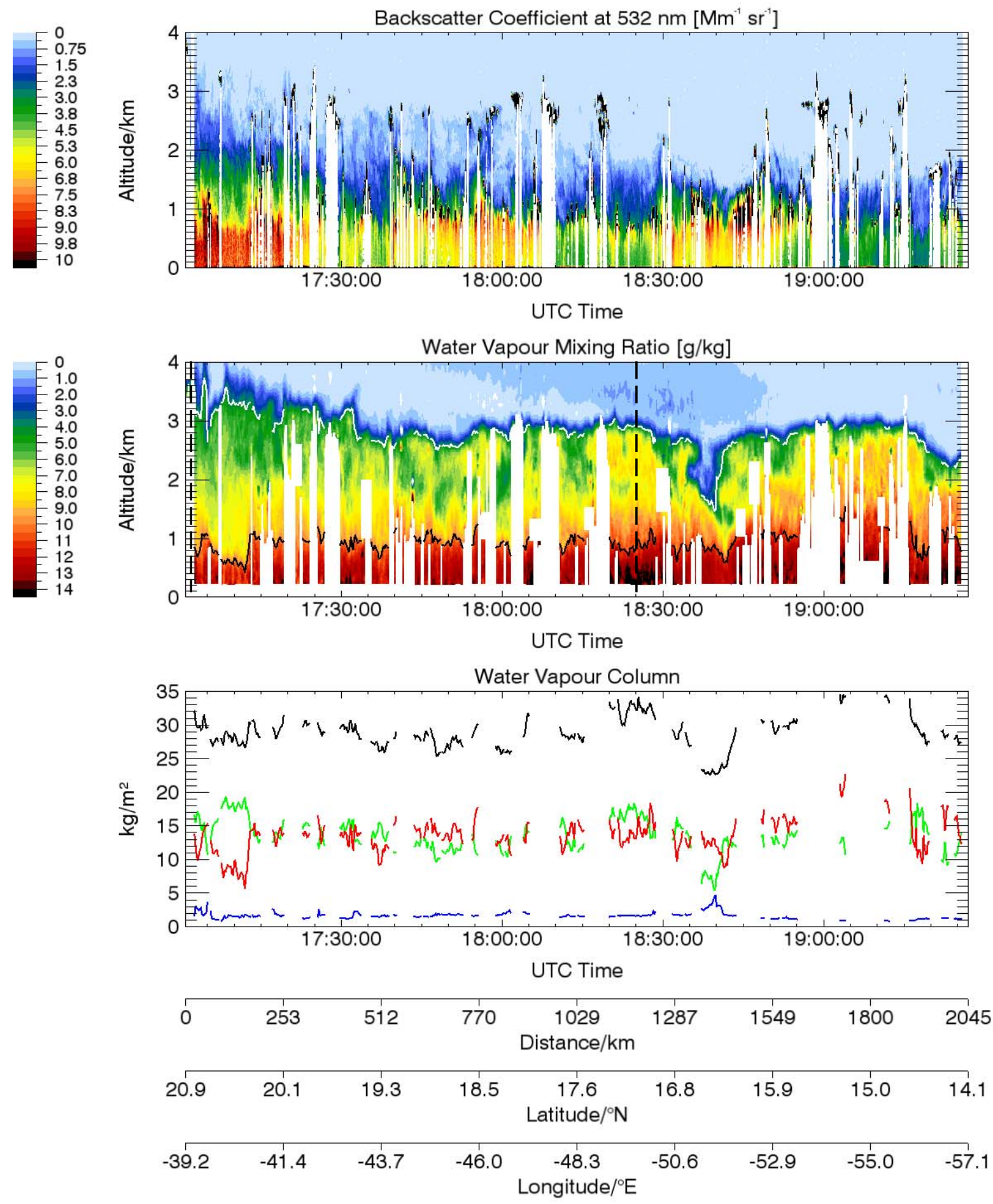

Figure 5: as Figure 3 but for the 19 Dec. 2013. The top of the cloud layer is defined by a mixing ratio of $4 \mathrm{~g} / \mathrm{kg}$ (white line), the top of the sub-cloud layer by $10 \mathrm{~g} / \mathrm{kg}$ (black line; $11 \mathrm{~g} / \mathrm{kg}$ after 18:20 UTC). 


\subsection{Transport of moisture through the cloud layer by shallow convection}

Figure 6 shows clouds again organized on large scales and a darker filament with few or no clouds between about $20^{\circ} \mathrm{N} / 43^{\circ} \mathrm{W}$ and $15^{\circ} \mathrm{N} / 58^{\circ} \mathrm{W}$ meandering about the flight trajectory. The MSG movie (not shown here) reveals that this filament persisted over the whole day, embedded in the trade wind flow moving westward. Similar filaments existed on other days of the campaign. Its darkest part was overflown between 19:00 - 19:25, and Figure 7 confirms the absence of clouds here. Earlier, the slimmer northeastern part of the filament was crossed at around 18:08 and 18:25, where the lidar backscatter also indicates cloud free conditions. The observations show that the width of the filament's cloud free core varies between 30 and $100 \mathrm{~km}$. All filament crossings show a significantly drier cloud layer in the water vapor cross section with around 7 instead of $9 \mathrm{~g} / \mathrm{kg}$ at 1500 $\mathrm{m}$ asl.

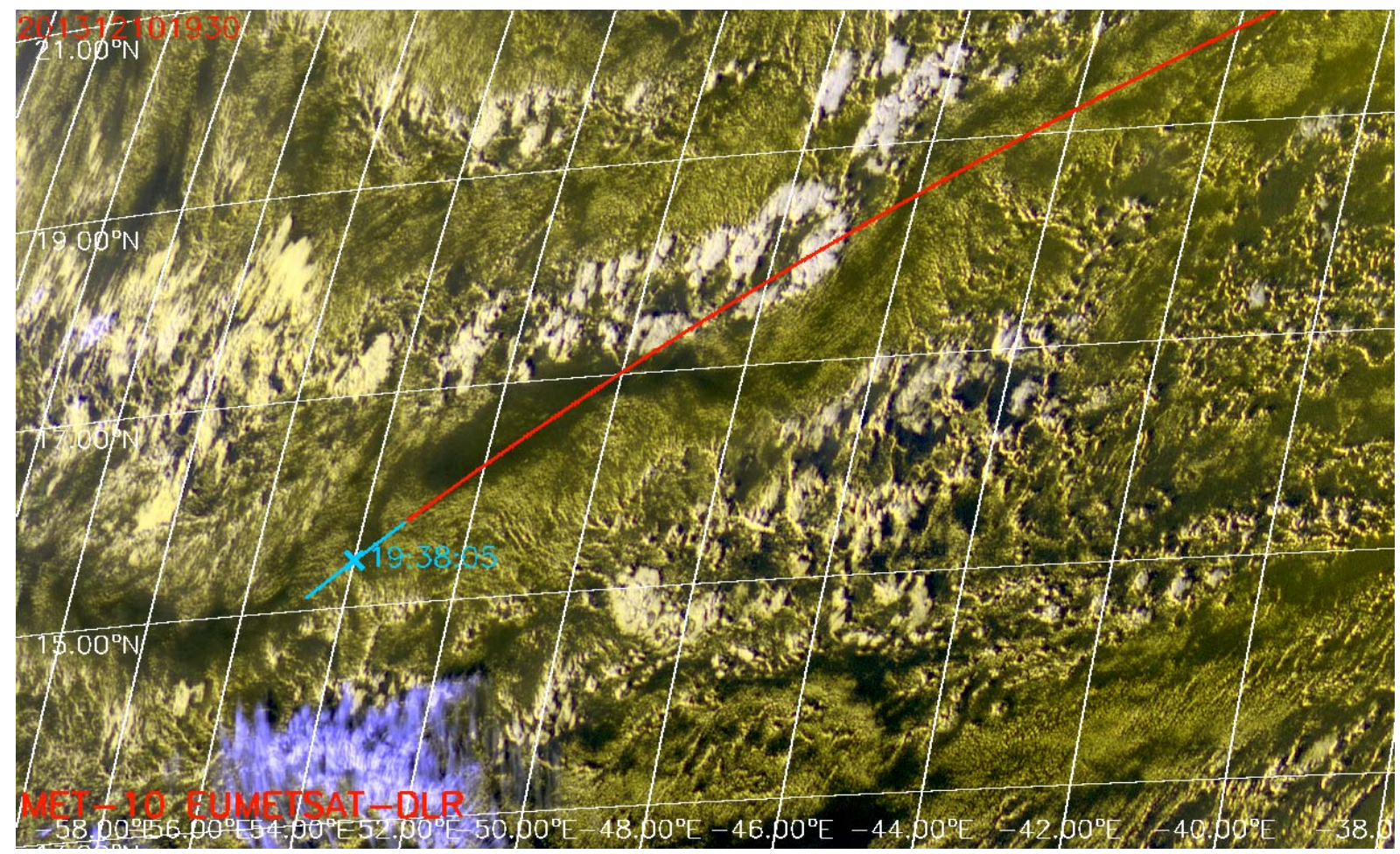

Figure 6: as Figure 2 but for the 10 Dec. 2013, 19:30. In the lower left, cirrus emanating from deep convection at the ITCZ located more south is apparent in violet. Aircraft flight track starting 17:50 (northeast end of red line), with 15-min segment around 19:38 UTC highlighted in blue, corresponding to the part of the flight path closest in time to this image.

This lidar segment displays an evident mechanism for upward transport, shallow convection. Figure 7 shows a heterogeneous cloud layer which the cloud convection has exceeded, giving a 200-km cloud topping between $2.5-2.8 \mathrm{~km}$ height and surrounded by a distinct elevated moist layer, vertically centered around $2.3 \mathrm{~km}$ asl. The higher humidity spans across $600 \mathrm{~km}$, between 18:20 - 19:05. The availability of 3 dropsondes, the one displayed in Figure $1 \mathrm{c}$ being just in the middle of the convective 
cluster, adds value to this case. They corroborate the lidar observation by indicating that convection has pushed the trade inversion upward by several $100 \mathrm{~m}$ and has significantly sharpened the moisture gradient at the height of the inversion. Table 1 also shows that the total column water vapor is augmented by $8.5 \mathrm{~kg} / \mathrm{m}^{2}$, or $30 \%$ in the $18: 50$ dropsonde, in agreement with the lidar water vapor columns (not shown here). Accordingly, the profiles of Figures $1 \mathrm{~b}$ and $1 \mathrm{c}$ are similar, except for the height of the inversion, whereas the 18:20 and 19:22 dropsondes (see Table 1) are more comparable to Figure 1a. The observed elevated cloud cluster likely represents a moisture elevator, although evidence could, as mentioned before, only be provided by additional observations of vertical movements or of convergence. Again, the lidar backscatter reveals a predominance of two cloud top heights, with the smaller, scattered clouds topping at about $1 \mathrm{~km}$ asl. While the cirrus in Figure 6 is well discernible, visual discrimination of the two different lower troposphere cloud top heights remains a challenge despite advanced imaging, mainly because the scattered clouds are too small and because Figure $1 \mathrm{c}$ reveals that the temperature difference between the two heights is just a few degrees and consequently too low to generate a discernible color contrast in the satellite images.
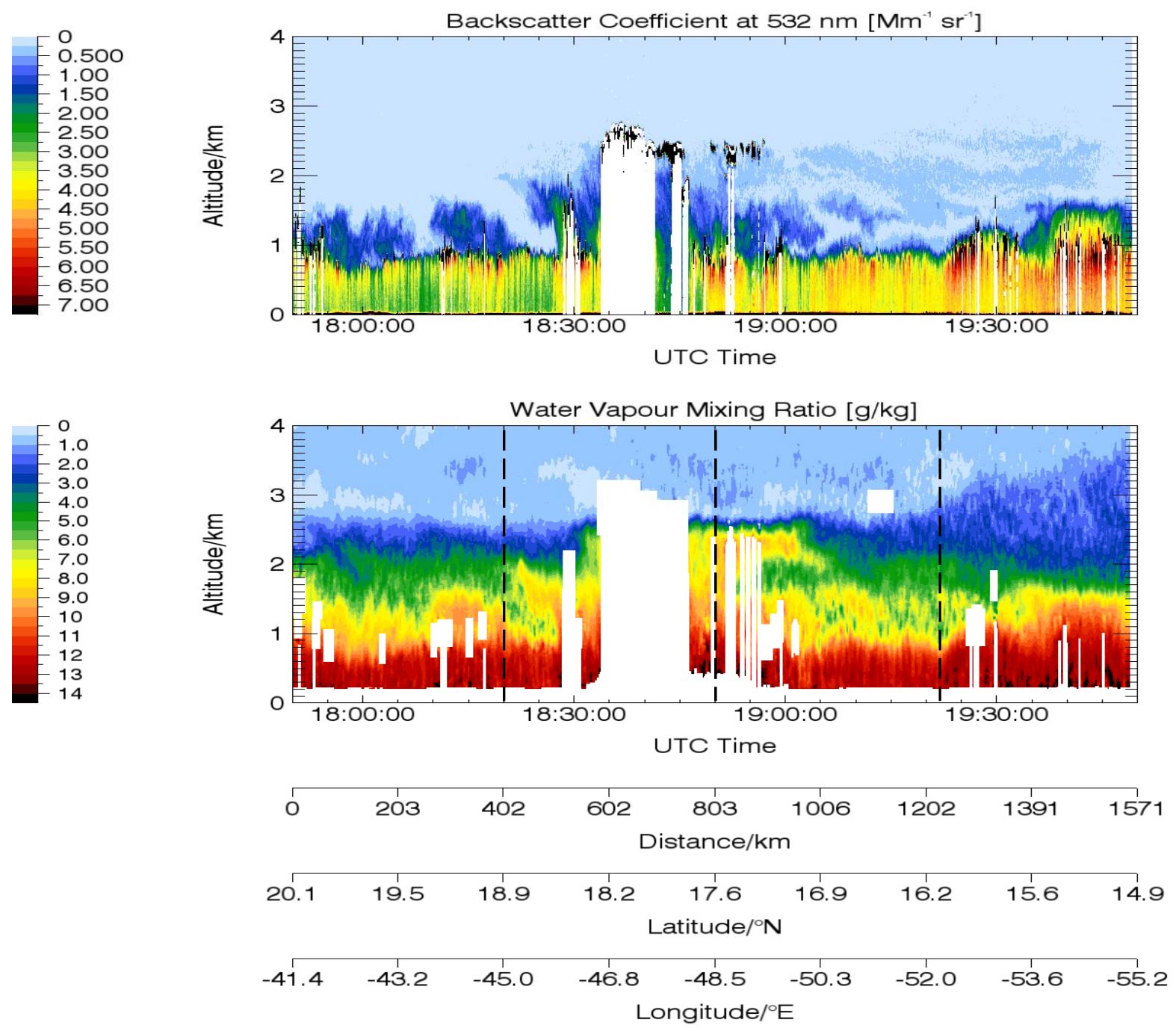

Figure 7: as Figure 3 but for the 10 Dec. 2013, and without the water vapor column panel. 
Figure 8 gives an impression how the convective cluster seen by the lidar in Figure 7 evolves over time. It is part of a larger circle of clouds with size $\sim 200 \mathrm{~km}$ around an inner cloud free region of $\sim 70$ $\mathrm{km}$ diameter. The circle appears having organized itself from less ordered cloud patches over the course of about $2.5 \mathrm{~h}$. The whole cluster moves southwestward with the trade winds of $\sim 12 \mathrm{~m} / \mathrm{s}$, which results in a displacement of $\sim 160 \mathrm{~km}$ over the 3:45 h time span, in agreement with Figure 8 . Generally, lidar results from repetitive overflights of the same region (not shown here) provide evidence that structures (variations) of the "background" humidity in the cloud layer remain discernable over at least some hours, similar to the cloud observations in Figure 8.

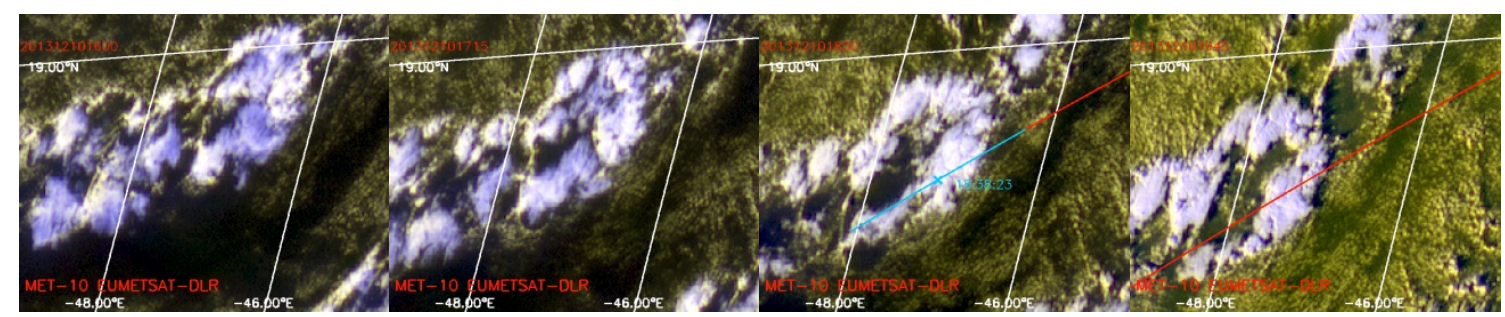

Figure 8: Temporal evolution on 10 Dec. 2013 from 16:00 to 19:45 UTC with 1:15 h increment of cloud cluster of Figure 7 as observed by MSG. Third image (18:30) incudes HALO flight path with timestamp. Fourth image is 15 min later than Figure 6 . The background varies due to changing solar illumination and cloud temporal evolution.

\subsection{Mean, Variance, and Skewness Profiles of Water Vapor}

Vertical profiles of statistical moments of horizontal water vapor lidar distributions between the clouds permit quantifying the variability for comparisons between the three presented cases, and with former studies. Profiles for the horizontal domains of Figures 3, 5 and 7, are shown in Figure 9. In Figures 9a and $b$ that present similarities, while the third case is different, the variance maxima coincide, as expected, with the heights of the strongest vertical moisture gradients located at the top of the cloud layer. The variance is proportional to the moisture jump across that boundary, with case a about twice as strong as case b. Below $1.5 \mathrm{~km}$ asl, the variances in a and b are similar. In contrast, the gradients at the top of the sub-cloud layer are so weak that the variances do not peak a second time there. Note that the mean profiles are smeared out by horizontal variability and that the vertical lidar resolution is $290 \mathrm{~m}$, while the local gradients may be much steeper, as we see in Figure 1. Case 3 is special. Due to the presence of two distinct convective regimes, one higher-reaching in the middle of Figure 7 and the other one surrounding it at lower levels, the mean profile in Figure 9c shows three layers and the variance profile has two distinct peaks. In all three cases the variance in the subcloud layer is lower than that in the cloud layer. A slight increase of the variance below $500 \mathrm{~m}$ asl may be indicative of instrumental noise that adds to the natural variance and increases with measurement range, i.e. augments the variance artificially towards the surface, as exemplified in Kiemle et al. (2007). Above its maximum at the trade inversion the variance abruptly decreases to very low levels up to the flight altitude. In comparison to fluctuations of water vapor in a convective boundary layer (CBL) over land, with smaller spatial scales and different origins of variability, we find up to 10 times stronger moisture variances. Kiemle et al. (1997 and 2007) derived mixing ratio 
variance profiles from $\mathrm{CBL}$ lidar curtains with maxima $<1(\mathrm{~g} / \mathrm{kg})^{2}$ at the top of the cloud-free $\mathrm{CBL}$ and mixing ratio jumps across the inversion comparable to those of the present case $b$. In the mid-CBL, their variances lie between $0.05-0.5(\mathrm{~g} / \mathrm{kg})^{2}$, after filtering out variance on scales larger than $\sim 10 \mathrm{~km}$ that were under-sampled. The comparison is consequently of limited value.

The skewness indicates the asymmetry of the water vapor distribution. A higher-order statistical moment, the skewness is more sensitive to outliers in the distribution, independent on whether they are real or measurement artifacts. Our interpretation consequently will be limited to the most prominent phenomena observed. In Figure 9a the skewness peaks at $2.5 \mathrm{~km}$ asl because of the presence of three upward protrusions of water vapor into the dry free atmosphere in Figure 3 at 20:10, 20:30, and 21:10. Conversely, the minimum at $1.7 \mathrm{~km}$ is related to the presence of two downward protrusions of dry air into the cloud layer at 20:15 and 20:45. Above 2.5 and below $1.7 \mathrm{~km}$ the skewness is insignificant, i.e. the distribution is symmetric about the mean. Maximum skewness in Figure $9 \mathrm{~b}$ is found above the trade inversion because of higher humidity in the very left of Figure 5. More interesting is the region with negative skewness below, deeper than in case a, related to the prominent downward protrusion of dry air into the cloud layer at 18:40. The vertical extent of negative skewness corresponds to the depth of the protrusion. Skewness values between 0 and -1 correspond to values found below the top of a CBL by Kiemle et al. (1997) due to narrow entrainment protrusions of dry air, yet, as noted for the variance, just the morphology corresponds, but the spatial scales and the atmospheric processes responsible for the observed variability are very different. For example, the CBL protrusions are typically $1 \mathrm{~km}$ in width, while the one at 18:40 is 100 $\mathrm{km}$ wide. It is consequently appropriate to consider the present horizontal scales of variability to be about 100 times larger. The skewness is negative also between altitudes of 0.5 and $1.1 \mathrm{~km}$, due to a suppressed sub-cloud layer around 17:10, again about $100 \mathrm{~km}$ large. Due to the two different regimes of convection and a consequently bimodal humidity distribution above $1.6 \mathrm{~km}$, the skewness profile of Figure $9 \mathrm{c}$ is only useful below this height, where we find relatively insignificant values again indicative of a balanced moisture distribution.
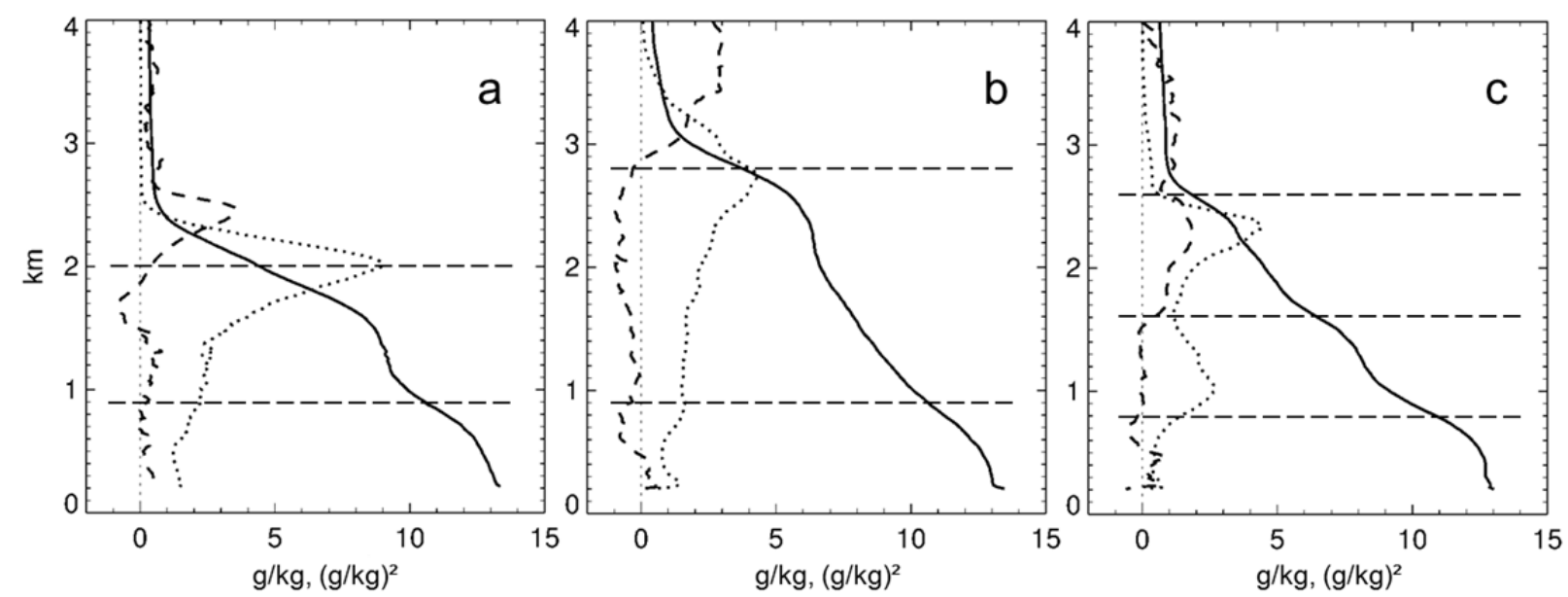

Figure 9: Profiles of mean (solid), variance (dotted) and skewness (dashed) of horizontal water vapor lidar distributions between the clouds on (a) 15., (b) 19., and (c) 10. Dec. 2013. Horizontal dashed lines: ( $a$ and $b$ ) average sub-cloud and cloud layer heights from black and white lines in Figures 3 and 5; in (c) the cloud layer has two distinct top heights. 


\section{Conclusions and Outlook}

Thanks to the capability of performing targeted, simultaneous measurements of aerosol or cloud backscatter and water vapor in regions of particular interest, an airborne water vapor lidar can help elucidate the complex interactions between water vapor, clouds and aerosol in the trades. During the HALO-NARVAL winter campaign in December 2013, high horizontal and vertical variability of humidity in the lower tropical troposphere, the omnipresence of an elevated moist layer with embedded clouds above the sub-cloud marine boundary layer, and high variability in the depth of those two layers were observed. The mixing ratio variance within the layers is up to 10 times larger than within a cloud-free CBL over land, at horizontal scales of variance about 100 times larger. The variance mainly stems from the presence of dry regions in the cloud and sub-cloud layers, and the transport of moisture through the cloud layer by shallow convection. In the majority of lidar and dropsonde profiles a strong temperature inversion and the strongest humidity gradient are located at the top of the cloud layer, while the sub-cloud layer top is characterized by weaker gradients of temperature and humidity. Conditional instability throughout the cloud layer creates an environment in which slight variations in temperature and humidity can have an impact on cloud depth and cover, thus creating the variability of cloud base and top heights observed within this layer.

Often, shallow convection is seen to precipitate, locally drying and cooling the atmosphere (Zuidema et al., 2012). We do not measure temperature by airborne lidar, but could, in the future, assess temperatures at the lifting condensation level when assuming that the lidar water vapor mixing ratio just at the top of the sub-cloud layer, below the base of optically thin clouds, corresponds to the saturation mixing ratio. Wherever the temperature lapse rate in the sub-cloud layer can be assumed dry-adiabatic as in Figure 1, we could extrapolate to the surface temperature and also obtain nearsurface relative humidities using the near-surface lidar mixing ratios. Additionally, conditional sampling of the water vapor lidar profiles around precipitating versus non-precipitating clouds may shed more light on the implications of precipitating shallow convection. Furthermore, investigations of a possible correlation between cloud cover and ambient column water vapor may complement the analyses of water vapor distributions in the vicinity of clouds. In order to better quantify the observed heterogeneity, variance and spectral analyses of the broader humidity fields and of the depths of both cloud- and sub-cloud layers are foreseen. Frequent gaps in the lidar data due to overlying clouds impede an easy approach, yet earlier work has opened ways to mitigate this issue (Kiemle et al., 2011). The observed intermittent character of convection in the cloud layer leads to water vapor distributions that may not be stationary enough for successfully applying Fourier analyses. For these cases well-documented alternative approaches exist to characterize variability, as exemplified in Fischer et al. (2013). In contrast with the present case study, future work will use all available water vapor lidar measurements from both NARVAL winter and summer campaigns to give resulting probability distribution functions and related statistics a broader basis, similar as in the comprehensive analyses performed by Randel et al. (2016).

With the absence of humidity and clouds above the trade inversion, the amount of outgoing longwave radiation and the related cooling rates are mainly governed by the trade inversion height and its variability. Lower heights increase the outgoing longwave radiation, yet the effects caused by such mesoscale variability on the trade wind layer are still fairly unknown. Future research could involve using the water vapor lidar profiles, together with auxiliary data as input for radiative transfer modelling to obtain estimates of the outgoing longwave radiation with high spatial resolution along the flight track. Recent model results suggest that low-level radiative cooling induces shallow 
circulations (Naumann et al., 2017). We hope that the presented lidar observations, as well as models accurately reproducing the observed variability will help evaluate the role that trade wind water vapor and its variability play for climate.

\section{Acknowledgements}

This paper arises from the International Space Science Institute (ISSI) workshop on "Shallow clouds and water vapor, circulation and climate sensitivity". Valuable support during the flight campaign was provided by Andreas Fix, Christian Büdenbender and Axel Amediek, all DLR. The NARVAL campaign was co-sponsored by the Max Planck Society, the Deutsche Forschungsgemeinschaft (German Science Foundation, project HALO-SPP 1294) and the DLR Institute of Atmospheric Physics. The dropsonde data were processed by Yanfei Gong, DLR, who also tested layer separation methods. We are grateful to Klaus Gierens, DLR, who provided an internal review, to Andreas Schäfler, DLR, for helpful discussions, and to an anonymous reviewer for many valuable comments.

\section{References}

Behrendt, A., V. Wulfmeyer, C. Kiemle, G. Ehret, C. Flamant, T. Schaberl, H.-S. Bauer, S. Kooi, S. Ismail, R. Ferrare, E. V. Browell and D. N. Whiteman, Intercomparison of Water Vapor Data Measured with Lidar during IHOP_2002. Part II: Airborne-to-Airborne Systems, J. Atmos. Ocean. Technol., 24, 22 39, 2007.

Bhawar R., et al., 2011: The Water Vapour Intercomparison Effort in the Framework of the Convective and Orographically-Induced Precipitation Study: Airborne-to-Ground-based and airborneto-airborne Lidar Systems. Q. J. R. Meteorol. Soc., 137, 325 - 348. DOI:10.1002/qj.697

Bielli, S., Grzeschik, M., Richard, E., Flamant, C., Champollion, C., Kiemle, C., Dorninger, M. and Brousseau, P. (2012), Assimilation of water-vapour airborne lidar observations: impact study on the COPS precipitation forecasts. Q.J.R. Meteorol. Soc.. doi: 10.1002/qj.1864

Bony, S., B. Stevens, D. Frierson, et al., 2015: Clouds, circulation, and climate sensitivity. Nature Geoscience, 8, 261-268. doi:10.1038/ngeo2398

Bony, S., B. Stevens, F. Ament, S. Crewell, J. Delanoe, D. Farrell, C. Flamant, S. Gross, et al., 2017: Towards EUREC^ $4 \mathrm{~A}$, a field campaign to elucidate the couplings between clouds, convection and circulation. This issue

Di Girolamo, P., A. Behrendt, C. Kiemle, V. Wulfmeyer, H. Bauer, D. Summa, A. Dörnbrack, G. Ehret, Simulation of satellite water vapour lidar measurements: Performance assessment under real atmospheric conditions. Remote Sensing of Environment, Vol. 112, Issue 4, pp. 1552-1568, 2008.

Fischer, L., G. C. Craig, and C. Kiemle, 2013: Horizontal structure function and vertical correlation analysis of mesoscale water vapor variability observed by airborne lidar. J. Geophys. Res., 118, 1-12. DOI: $10.1002 /$ jgrd.50588. 
Flentje, H., A. Dörnbrack, G. Ehret, A. Fix, C. Kiemle, G. Poberaj and M. Wirth, 2005: Water vapour heterogeneity related to tropopause folds over the North Atlantic revealed by airborne water vapour differential absorption lidar, J. Geophys. Res. 110, D03115, doi:10.1029/2004JD004957.

Groß, S., Wirth, M., Schäfler, A., Fix, A., Kaufmann, S., and Voigt, C., 2014: Potential of airborne lidar measurements for cirrus cloud studies, Atmos. Meas. Technol., 7, 2745-2755.

Gutleben, M., Groß, S., Wirth, M., Ewald, F. and Schäfler, A.: Applicability of spaceborne lidar measurements to study shallow marine convection over the subtropical North Atlantic Ocean. To be submitted to AMT, 2017.

Kiemle, C., G. Ehret, A. Giez, K. J. Davis, D. H. Lenschow, S. P. Oncley: Estimation of boundary-layer humidity fluxes and statistics from airborne differential absorption lidar (DIAL). J. Geophys. Res., Vol. 102 No. D24, 29189-29203, 1997.

Kiemle, C., W. A. Brewer, G. Ehret, R. M. Hardesty, A. Fix, C. Senff, M. Wirth, G. Poberaj, M. A. LeMone: Latent Heat Flux Profiles from Collocated Airborne Water Vapor and Wind Lidars during IHOP_2002. J. Atmos. Ocean. Technol., 24, 627 - 639, DOI: 10.1175/JTECH1997.1, 2007.

Kiemle, C., M. Wirth, A. Fix, G. Ehret, U. Schumann, T. Gardiner, C. Schiller, N. Sitnikov, and G. Stiller, 2008: First airborne water vapor lidar measurements in the tropical upper troposphere and midlatitudes lower stratosphere: accuracy evaluation and intercomparisons with other instruments. Atmos. Chem. Phys. 8, 5245-5261.

Kiemle C., M. Wirth, A. Fix, S. Rahm, U. Corsmeier, P. Di Girolamo, 2011: Latent heat flux measurements over complex terrain by airborne water vapour and wind lidars. Q. J. R. Meteorol. Soc. 137, 190 - 203. DOI:10.1002/qj.757.

LeMone, M. A. and W. T. Pennell, 1976: The Relationship of Trade Wind Cumulus Distribution to Subcloud Layer Fluxes and Structure. Mon. Wea. Rev. 104, 524-539.

Mech, M., Orlandi, E., Crewell, S., Ament, F., Hirsch, L., Hagen, M., Peters, G., and Stevens, B. , 2014: HAMP - the microwave package on the High Altitude and LOng range research aircraft (HALO), Atmos. Meas. Tech., 7, 4539-4553, doi:10.5194/amt-7-4539-2014.

Naumann, A.-K., Stevens B., Hohenegger C., Mellado J. P., 2017: A conceptual model of a shallow circulation induced by prescribed low-level radiative cooling. J Atmos Sci p submitted

Nehrir, A. R., C. Kiemle, M. Lebsock, G. Kirchengast, S. Buehler, et al., 2017: Emerging Technologies and Synergies for Airborne and Space-Based Measurements of Water Vapor Profiles. This issue

Nuijens, L., B. Medeiros, I. Sandu and M. Ahlgrimm, 2015: Observed and modeled patterns of covariability between low-level cloudiness and the structure of the trade-wind layer. J. Adv. Model. Earth Syst., 7, doi:10.1002/2015MS000483.

Pincus, R., A. Beljaars, S. Buehler, G. Kirchengast, F. Landstaedter, J. Whitacker, 2017: The distribution of water vapor over low-latitude oceans. Current best estimates, errors, and impacts. This issue 
Prospero, J. M., F.-X. Collard, J. Molinié, and A. Jeannot, 2014: Characterizing the annual cycle of African dust transport to the Caribbean Basin and South America and its impact on the environment and air quality. Global Biogeochem. Cycles, 29,757-773, doi:10.1002/2013GB004802.

Randel, W. J., L. Rivoire, L. L. Pan, and S. B. Honomichl, 2016: Dry layers in the tropical troposphere observed during CONTRAST and global behavior from GFS analyses. J. Geophys. Res. Atmos., 121, 14,142-14,158, doi:10.1002/2016JD025841.

Schäfler, A., A. Dörnbrack, C. Kiemle, S. Rahm, M. Wirth, 2010: Tropospheric Water Vapor Transport as Determined from Airborne Lidar Measurements. J. Atmos. Oceanic Technol., 27, 2017-2030. doi: 10.1175/2010JTECHA1418.1

Schmetz, J., P. Pili, S. Tjemkes, D. Just, J. Kerkmann, S. Rota, and A. Ratier, 2002: An introduction to Meteosat Second Generation (MSG). Bull. Amer. Meteor. Soc., 83, 977-992, doi:10.1175/15200477(2002)083<0977:AITMSG>2.3.CO;2.

Sherwood, S. C., S. Bony and J-L. Dufresne, 2014: Spread in model climate sensitivity traced to atmospheric convective mixing. Nature 505, 37-42.

Stevens, B., 2005: Atmospheric Moist Convection. Annu. Rev. Earth Planet. Sci., 33, 605 - 643. doi: 10.1146/annurev.earth.33.092203.122658

Stevens, B., H. Brogniez, C. Kiemle, J.-L. Lacour, C. Crevoisier, J. Killiani, 2017: Structure and dynamical influence of water vapor in the lower tropical troposphere. This issue

Stull, R., 2015: "Practical Meteorology: An Algebra-based Survey of Atmospheric Science." Univ. of British Columbia. 938 pages. isbn 978-0-88865-176-1

Trickl, T., et al., 2016: How stratospheric are deep stratospheric intrusions? LUAMI 2008. Atmos. Chem. Phys., 16, 8791-8815. www.atmos-chem-phys.net/16/8791/2016/. doi:10.5194/acp-16-87912016.

WCRP, 2016: http://wcrp-climate.org/index.php/gc-clouds

Wirth, M., A. Fix, P. Mahnke, H. Schwarzer, F. Schrandt, G. Ehret, 2009: The airborne multiwavelength water vapor differential absorption lidar WALES: System design and performance. Appl. Phys. B 96: 201-213.

Wulfmeyer, V., R.M. Hardesty,D. D. Turner, A.Behrendt, M.P.Cadeddu, P. Di Girolamo, P. Schlüssel, J. Van Baelen, and F. Zus (2015), A review of the remote sensing of lower tropospheric thermodynamic profiles and its indispensable role for the understanding and the simulation of water and energy cycles, Rev. Geophys., 53, 819-895, doi:10.1002/2014RG000476.

Zuidema, P., et al., 2012: On Trade Wind Cumulus Cold Pools. J. Atmos. Sci., 69, 258-280. DOI: 10.1175/JAS-D-11-0143.1

Zuidema, P., and G. Torri, 2017: Precipitation-induced oceanic cold pools and their interactions with the larger-scale environment. This issue 